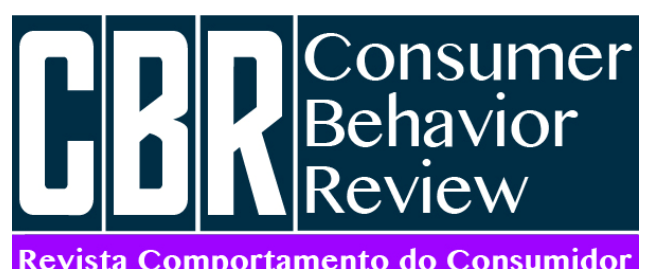

Revista Comportamento do Consumidor
Damascena, E. O. \& Arruda, K. F. (2017). A voz do vício: As atitudes de jovens fumantes e não-fumantes quanto ao endosso do consumo de cigarros em videoclipes. Consumer Behavior Review, 1(Special Edition), 92-106.
ISSN: 2526-7884

Editor: Prof. Dr. Marconi Freitas da Costa Email da revista: cbr@ufpe.br
Avaliação: Double blind review

Recebido: 05 de julho de 2017

Aceito: 10 de setembro de 2017

\title{
A VOZ DO VÍCIO: AS ATITUDES DE JOVENS FUMANTES E NÃO-FUMANTES QUANTO AO ENDOSSO DO CONSUMO DE CIGARROS EM VIDEOCLIPES
}

\author{
Elielson Oliveira Damascena \\ Kamila Freitas De Arruda
}

Elielson Oliveira Damascena é Professor da Universidade Federal de Pernambuco,

Campus Caruaru - UFPE. E-mail: elielson_damascena@yahoo.com.br. Kamila Freitas da Arruda é graduada em Administração pela Universidade Federal de Pernambuco, Campus Caruaru - UFPE. Email: milaarruda16@gmail.com.

Os autores agracedecem aos avaliadores pelos comentários para melhoria do artigo.

\begin{abstract}
Resumo
Esta pesquisa busca analisar as atitudes apresentadas por jovens frente à inserção de cigarros em videoclipes. Tratase de uma pesquisa de cunho descritivo-exploratório, que procura suas respostas a partir da relação direta e interativa com o pesquisado, a partir de entrevistas individuais, de modo a entender o fenômeno sob a perspectiva do entrevistado. Foram apresentados dois clipes entre os mais visualizados da Billboard e a análise de dados foi feita a partir da técnica análise de conteúdo. Ao fim da pesquisa, nota-se que (1) jovens fumantes são mais liberais que os não-fumantes em relação à exibição do cigarro em videoclipes; (2) o marketing é bem sucedido ao passo que ver outras pessoas fumando influencia fumantes a continuar no hábito; (3) amigos, família e status influenciam tanto quanto ver outra pessoa fumar e; (4) o uso de endossantes nesse tipo de merchandising é bem sucedido para quem admira os artistas.

Palavras-chave: Merchan music, Atitude do consumidor, Cigarro, YouTube, Endossantes.
\end{abstract}

Esta obra está licenciada com uma Licença Creative Commons Atribuição 4.0 Internacional.

\section{INTRODUÇÃO}

Publicidade é toda a forma de comunicação realizada por meio de mensagens, anúncios e mídia em geral, com vista a espalhar e expandir um produto ou ideia e, da mesma forma, alterar comportamentos (Lovison \& Petroll, 2010). Em suas mais diferentes fases ao longo de sua 
evolução - desde o seu surgimento até agora - o conceito é trabalhado como uma forma de impor e estereotipar positivamente o produto e/ou serviço que está sendo divulgado (Muniz, 2004). Deste modo, conforme o autor, o conceito pode ser definido como a capacidade de induzir e despertar no público o desejo de compra do produto e/ou serviço que está sendo veiculado.

Lipovetzky (2000) vai contra esta ideia, ao afirmar que a publicidade não é capaz de fazer desejar o indesejável. Ela é, então, apresentada por ele como um jogo de sedução, onde desempenha o papel de fazer com que o produto oferecido seja visto como desejável. Logo, o termo poderia ser comparado com os conceitos de estímulo e motivação. A publicidade, então, seria o equivalente ao estímulo. Ela gera uma alteração positiva na psique do indivíduo, mas não é capaz de gerar uma motivação ao hábito de consumo. A decisão de consumir não cabe à publicidade, e sim ao consumidor. "Só se pode seduzir alguém que já esteja predisposto a ser seduzido" (Lipovetzky, 2000, p. 09).

Na era moderna, onde maciça parte da população vive conectada, utilizar as mídias da internet para a publicidade em geral é algo que se tornou fundamental. 0 público jovem migrou quase por completo da TV para a internet numa busca incessante por novidades e disponibilidade de música (Zanetti \& Belo, 2012). Na internet, segundo pesquisa realizada pelo Google Brasil no ano de 2015, o site mais utilizado pelos brasileiros para assistir esses vídeos é o YouTube, representando 95\% do total de usuários pesquisados. 0 site ganha cada vez mais espaço no cenário da mídia.

Com seu exponencial crescimento, principalmente em publicidade e propaganda dentro dos vídeos, é plausível afirmar que a utilização do site para este fim é uma das maneiras mais eficazes de alcance do público jovem.Com o advento do YouTube, os videoclipes ganharam ainda mais destaque do que quando eram veiculados apenas na TV. 0 gênero é hoje um dos modelos audiovisuais mais vistos na web (Romero \& Centellas, 2008).

Dentro deste contexto, a promoção do cigarro vinculada à internet gera sérios impactos no público da rede. Quando essa promoção acontece no YouTube e, mais especificamente, nos videoclipes, tal impacto é ainda maior, uma vez que aumenta a sua proximidade com os jovens. Segundo Soares (2012), o videoclipe se aproxima do conceito de simulação ou da consciência de uma realidade simulada, uma vez que foi, aos poucos, desenvolvido para aludir e iludir o expectador com relação à determinada ação, contexto, lugar, etc. Soares (2012) explica que eles compõem uma amostra de venda, ou seja, são produzidos como uma estratégia de venda "caracterizada por uma noção de ritmo. 0 ritmo das imagens" (Soares, 2012. p. 32). Deste modo, os videoclipes tornam-se símbolo de status, moda e estilo; assim como o tabaco é, em geral, retratado. Ao juntar os dois, obtemos uma "arma" de venda e sedução ao cigarro e afins.

Segundo dados de 2013 da Organização Mundial da Saúde (OMS), o vício em tabaco inicia antes dos 20 anos de idade. Em contra partida, apesar de proibida de agir massivamente no Brasil desde o ano 2000, o Marketing do cigarro permanece buscando meios alternativos de promover seu produto voltado para os jovens - especialmente adolescentes, que se encontram numa fase mais influenciável da vida - de uma maneira que as campanhas antitabagistas jamais se igualariam. Araújo (2010) atribui isso ao fato da adolescência ser um período de rebeldia contra valores estabelecidos pelos adultos.

Pensando nisso, o Marketing investido na área é voltado exatamente para eles e, principalmente, aos níveis mais baixos de renda, uma vez que estes possuem maior probabilidade de experimentar o cigarro pela primeira vez, por este ser um produto de baixo custo e que "agrega" alto valor psicológico: Glamour, luxo, sucesso, etc. Ou seja, o ato de experimentar o cigarro está ligado a uma busca por identidade e aceitação no mundo adulto, figurado principalmente pelos pais e por seus ídolos da cultura pop (Reinaldo et al. 2010 \& Araújo, 2010). Em sua defesa, a indústria alega que é a pressão de terceiros e não a publicidade da área que influencia a iniciação ao tabagismo (Filho \& Caprino, 2006).

Afora os problemas relacionados à saúde física, a OMS destaca que jovens fumantes são mais propensos a desenvolver problemas emocionais e psicológicos. 0 tabagismo causa quase cinco milhões de mortes por ano em todo o mundo e é destacado por Borges e Barbosa (2009), como entrelaçado nos mais diversos 
processos sociais, econômicos, governamentais, agricultura, entre outros. Para ser combatido, é preciso que ele seja enxergado como um fenômeno complexo e multifacetado. Araújo (2010) destaca que, quando jovens experimentam o cigarro pela primeira vez, possuem grande probabilidade de se tornarem fumantes. Além disso, "a iniciação precoce ao fumo é preditora do uso de outras substâncias como álcool e drogas ilícitas" (Araújo, 2010, p. 672). É o mesmo que a OMS acredita quando diz que jovens fumantes são oito vezes mais propensos a usar maconha e vinte e duasvezes mais propensos a usar cocaína.

Apesar de proibida toda e qualquer propaganda midiática referente ao uso do cigarro, não é difícil encontrar apologias ao tabaco em novelas, filmes, revistas e vídeos (Reinaldo et al. 2010). Um estudo do Reino Unido realizado entre os anos de 1999 e 2004 revelou que a exposição de jovens a publicidade de cigarro, mesmo que pela primeira vez, aumenta suas chances de fumar em 7\%. 0 desafio é controlar este tipo de ação ainda não regulamentada pelas leis.

Conforme Mirra et al (2013), além da questão social relacionada aos efeitos do tabaco sobre a saúde humana, a questão do cigarro e de seus derivados englobam também a esfera ambiental e econômica. Esta última em especial, pois, segundo pesquisa realizada pela Aliança de Controle do Tabagismo (ACT), o tabaco acarretou apenas em 2011 um gasto de $R \$ 23$ bilhões com despesas ao Sistema Único de Saúde (SUS), referentes à hospitalização com doenças tabaco-relacionadas. 3,5 vezes maior do que a Receita Federal arrecadou com a comercialização do produto no mesmo ano (Mirra et al. 2013; ACT, 2011).

A Transformative Consumer Research (TCR) surgiu em 2005 e aparece como uma forma de trazer à luz da investigação científica a preocupação com o consumidor, abordando temas como o consumo do cigarro, drogas, álcool, alimentos não saudáveis, etc., bem como em enfatizar a sua satisfação ao consumir tais produtos, gerando resultados para benefício próprio e para a sociedade (Coelho, 2015; Mick, 2006). Muitos dos problemas mundiais poderiam ser gerados ou agravados pelo consumoe, são raras as vezes em que uma pesquisa é desenvolvida visando o ponto de vista do consumidor. Pelo contrário, a ênfase predomina no tripé (1) mente humana, (2) aquisição de bens e (3) sucesso organizacional. Apesar de ainda embrionária, a TCR justifica sua importância acadêmica ao expor ao público a disseminação de um problema social sob a ótica da ciência (Coelho, 2015).

Quando apontada a partir do prisma do tabaco, a TCR discute as consequências físicas e psicológicas do uso do cigarro em seus consumidores, além de realizar uma crítica às ações do Marketing para incentivar o uso do produto. 0 que a TCR busca é entender, divulgar e expandir este tipo de estudo, visando o bem estar de quem faz uso dele. Araújo (2010) afirma que a pesquisa em áreas de prevenção a iniciação ao consumo de drogas em geral são fundamentais para se pensar políticas públicas de ações preventivas ao caso.

Por fim, esta pesquisa objetiva analisar as atitudes apresentadas por jovens fumantes e não-fumantes frente ao endosso do consumo de cigarros em videoclipes.

\section{FUNDAMENTAÇÃO TEÓRICA}

\section{Atitude do consumior}

Mooij (2011) classifica o termo atitude como a predisposição individual de avaliar um objeto ou classe de objetos como favorável ou não e que, de alguma forma, leva ao consumo. $\mathrm{O}$ autor ainda acrescenta que ela é formada por componentes afetivos e cognitivos, incluindo sensações, sentimentos e emoções e, nos componentes cognitivos, podem ser incluídos os diversos tipos de atributos e funções do objeto. Além disso, Solomon (2002) destaca que a atitude em si deriva de três elementos: (1) afeto ou affect - como o consumidor se sente em relação ao objeto de atitude; (2) comportamento ou behavior - as intenções do consumidor em relação ao objeto de atitude e; (3) cognição ou cognition - suas crenças com relação ao objeto de atitude. Os três segmentos compõem o que os pesquisadores chamam de "Modelo ABC de Atitudes" e interliga as funções: conhecer, sentir e fazer.

Em outras palavras, a atitude do consumidor de cigarros, bem como a do expectador da publicidade do tabaco, não é determinada apenas pelas suas crenças pessoais do que é o cigarro e do que ele representa para a vida física e emocional, mas, também é uma ação determinada por um conjunto de, no mínimo, 
três elementos que, juntos, e dispostos das mais variadas maneiras, exercem função de importância na geração de valor e atitude do consumidor (Solomon, 2002).

Neste caso, entende-se que as atitudes podem ser influenciáveis e, tendo isso em vista, o Marketing pode gerar ações plausíveis para isso (Solomon, 2002). Isso resulta no que o autor chama de Paradoxo do Envolvimento, ou seja, "quanto menos importante é o produto para os consumidores, mais importantes são muitos dos estímulos de Marketing [...] que devem ser criados para vendê-lo" (p. 168). Em outra perspectiva, a publicidade e a propaganda, muitas vezes, se apoiam na premissa de que os consumidores tendem a imitar o comportamento de modelos desejáveis (Solomon, 2002). Assim, é útil conhecer as atitudes a fim de identificar seus níveis de confiança e convicção para, a partir disso, traçar estratégias publicitárias capazes de influenciálas (Solomon, 2012).

\section{O uso de endossantes na publicidade}

Diversas empresas fazem uso em suas campanhas dos chamados endossantes. Endossantes são pessoas, em geral públicas, pagas para figurar em anúncios e propagandas de produtos e/ou serviços em geral. Normalmente a ideia desejada pelas empresas é mostrar ao público que aquele artista faz uso de seu produto, o recomenda para a população eque influencia as atitudes dos consumidores em relação a sua oferta de produto, gerando a chamada interiorização que, segundo Shimp (2009), é um processo psicológico de aceitação e formação de opinião a respeito do produto apresentado a partir da opinião do endossante.

Araújo (2010) apresenta que os endossantes têm sido bastante utilizados na propaganda e publicidade do tabaco. Isto, pois, cada vez mais cresce o número de cenas inseridas nas mídias que mostrem atores fumando, fazendo com que adolescentes assistam e passem a ter maior probabilidade de se tornarem fumantes também.

Outro recurso estratégico do Marketing para as campanhas publicitárias é a utilização da música. Segundo Shimp (2009), a música mostra sua importância por chamar atenção, tornar os expectadores mais receptivos e transmitir informações sobre o que está sendo anunciado. Cardoso, Gomes e Freitas (2010) afirmam que utilizada nos anúncios, a música adequada desempenha o papel de individualizar uma comunicação desenvolvida para uma grande massa e estimular o consumidor. Os mesmos autores explicam que a música estende o prazo de vida do anúncio por se manter na memória dos consumidores por mais tempo que os anúncios sem música e são positivos na memorização da marca.

\section{A publicidade de cigarros Breve histórico da publicidade de cigarros}

Desde os seus primeiros cartazes de publicidadeséculo XVIII, o cigarro era atribuído a coisas boas. E, desde o início, a publicidade do cigarro sempre esteve ligada a dois tipos básicos: a favor, que mostrava todos os atributos destacados como provenientes do cigarro, como masculinidade, sociabilidade, etc.; e contra, que mostrava a realidade dos estragos provocados pelo fumo (Moutinho, 2008).

Com a Primeira Guerra Mundial, o público feminino foi inserido no mercado de trabalho e, consequentemente, também nas propagandas de cigarro (Sasaki, 2010). Isso não impediu a promoção do tabaco entre os homens de guerra, uma vez que as empresas tabagistas enviavam, de graça, maços de cigarros para os combatentes de guerra em suas rações de comida (Moutinho, 2008). 0 acontecimento acarretou um aumento na venda de cigarros no pós-guerra (Randall, 1999). Já com a chegada do cinema, atores passaram a ser pagos para fumar em cena e a sensualidade da mulher no mesmo contexto construiu um imaginário de que fumar gera um prazer e sucesso inquestionáveis (Sasaki, 2010; Vergara \& Aquino, 2003).

Chegava a vez então de trazer a publicidade do tabaco para a televisão, e chamar desportistas, atores, crianças e até mesmo médicos para endossarem o produto $\mathrm{e}$ responderem às críticas maciças dos grupos antitabaco (Reis, 2012; Moutinho, 2008; Vergara \& Aquino, 2003). Na década de 1950, iniciaram as primeiras pesquisas científicas sobre as consequências do cigarro e por volta de 1960 passou-se a divulgar características como sabor e a aparência das embalagens (Vergara \& Aquino, 2003; Randall, 1999).

A partir do fim dos anos 1970, a indústria tabagista descobriu a propensão dos jovens de 
se tornarem fumantes se estimulados da maneira certa. A publicidade passou então a abordar o cigarro como diretamente relacionado ao esporte, aventura e introdução ao mundo adulto e só a partir da década de 1990 é que surgiram as primeiras proibições concretas a respeito do uso e divulgação dos produtos no Brasil (Vergara \& Aquino, 2003).

\section{Regulamentação da publicidade do tabaco no Brasil}

Segundo Romero e Silva (2011), a atuação do governo federal na luta contra o tabagismo no Brasil começou a tomar forma em 1985, com a criação de importantes programas como o Programa Nacional de Combate ao Fumo (PNCF) e a associação dos programas antitabaco com o Instituto Nacional do Câncer (INCA), hoje o órgão oficial de combate ao fumo no Brasil (Araújo, 2010). No ano de 2003, foi aprovada a Convenção Quadro para Controle do Tabaco (CQCT). A CQCT, entre outras coisas, estipulou a proibição total da publicidade do cigarro e derivados no país, o que se confirma na Lei Federal 9.294 que estabelece a restrição do uso da propaganda de produtos fumígeros, exceto nos locais de venda dos produtos, desde que acompanhada das advertências textuais e visuais dos riscos à saúde que seu uso pode causar (CQCT, 2005; Planalto, 1996).

Em 2011 surge a Lei no 12.546 que veta todo e qualquer tipo de: (1) venda postal; (2) distribuição de amostras e brindes; (3) propaganda em meios eletrônicos, inclusive via internet; (4) distribuição gratuita; (5) patrocínio de atividades culturais ou esportivas; (6) propaganda fixa em locais de grande circulação de pessoas; (7) propaganda indireta - merchandising em programas produzidos no Brasil; (8) comercialização em órgãos públicos e; (9) venda a menores de dezoito anos (Planalto, 2011).

Ainda na Lei no 12.546 , foi estabelecido que a taxação da comercialização de cigarros passasse a ser de $70 \%$ do preço do consumidor, em acordo com as indústrias do produto (Planalto, 2011; Romero \& Silva, 2011). Mesmo assim, tal política não afetou os preços das carteiras de cigarro no país, que ainda figuram entre as mais baratas do mundo, facilitando o seu acesso (Romero \& Silva, 2011; Silva et al. 2014; Vergara \& Aquino, 2003). Além destas principais Leis, há ainda diversos decretos, resoluções e portarias que fortalecem e especificam o conteúdo das Leis citadas.

\section{A realidade atual da comunicação do tabaco}

Apesar de proibida toda e qualquer propaganda e/ou publicidade do tabaco nas mídias nacionais e internacionais, a indústria do cigarro e derivados promove sua divulgação nos mais diversos meios de comunicação, envolvendo desde jogos eletrônicos até filmes e novelas. Fazem isso, claro, utilizando estratégias de marketing que coloquem o ato de fumar como algo agradável e necessário ao mundo adulto, "como um ícone de amadurecimento e ideal de autoimagem, incentivando a experimentação" (Araújo, 2010, p. 673).

0 consumo do cigarro continua a crescer em todo o mundo e isto se deve aos esforços do marketing para a promoção do produto (Mirra et al., 2013). É comprovado cientificamente que a proibição completa da publicidade e/ou promoção, além do patrocínio, do tabaco, é eficiente na luta pela redução do consumo do cigarro e seus derivados. Por outro lado, a proibição parcial não gera quase nenhum efeito sobre o assunto (Mirra et al., 2013). Assim, para o mesmo autor, a proibição da exposição do tabaco e do seu uso deve ser controlada de maneira firme e completa, visto que tal exibição influência a iniciação ao fumo.

Santos e Grossi (2007) afirmam que jovens e adolescentes são expostos a cerca de $40 \mathrm{mil}$ propagandas por ano. O problema está em pensar que não há nenhum tipo de proibição do marketing do tabaco junto aos jovens, funcionando como propaganda subliminar (Araújo, 2010). 0 fato preocupa pela frágil formação da personalidade desses jovens (Santos \& Grossi, 2007). Mirra et al. (2013) corroboram com essa ideia quando afirmam que quanto maior o número de publicidade a que um adolescente é exposto, maior é a probabilidade dele experimentar o cigarro pela primeira vez.

\section{A publicidade de cigarros na Web}

De acordo com a Lei Federal no 9.294, a veiculação de publicidade do tabaco virtual e na internet é proibida, inclusive o merchandising produzido dentro do país. Apesar disso, tal Lei é vigente apenas no Brasil. Deixando livre a 
visualização de mensagens subliminares, referências e até o próprio merchan produzido fora do Brasil.

Conceição et al. (2014) afirma que os modernos modelos audiovisuais possibilitam uma ampla gama de influências na mídia, o que abre vastos caminhos para o marketing se comunicar e ousar, como nos videoclipes de astros da música pop. É o merchan music. Os autores explicam que este novo tipo de comunicação em marketing tem ganhado força, pois, permite que o público seja influenciado pelos seus ídolos musicais, fazendo com que os consumidores atribuam automaticamente ao que lhes são apresentados a imagem positiva e de objeto de desejo. Isso se comprova se pensarmos que os fãs fazem de tudo para se sentirem próximos de seus ícones (Conceição et al., 2014).

Assim, muitas empresas optam cada vez mais por realizar suas divulgações em ambientes diferenciados, como nos videoclipes, o que os permite uma diferenciação de seus concorrentes. 0 merchan music em videoclipes é uma alternativa viável para atingir públicos específicos, aumentando as chances de afetar com suas mensagens. Assim, o merchandising em clipes de música está se tornando uma importante ferramenta de marketing, por atingir uma geração que passa $24 \mathrm{~h}$ do dia conectados (Conceição et al., 2014).

Sabendo disso, e como esse tipo de publicidade possui o intuito de anunciar em veículos de massa, o YouTube assume seu papel de importância, uma vez que é a principal plataforma de visualização de vídeos e videoclipes do Brasil e é acessado milhões de vezes ao dia (Think With Google, 2015 e Conceição et al., 2014). Além das questões já levantadas, Soares (2012) apresenta o videoclipe vendedor da canção e de tudo o que existe nele. $\mathrm{O}$ autor completa que o "clímax" da música, a parte do videoclipe que convoca a atenção do expectador, ativa o que ele chama de "refrão visual". É neste ponto do videoclipe que imagens produzidas pelo produtor da obra se projetam em direção ao público. Seduzindo, atraindo e construindo uma imagética associativa que vai habitar na mente dos expectadores/consumidores.

No contexto deste trabalho, a utilização do merchan music do cigarro em videoclipes estrangeiros seria introduzido em vídeo como uma performance da música, sendo o produto tabagístico utilizado pelo artista ou por algum personagem importante do ambiente, de modo a ser enfatizado num possível "refrão visual" (Soares et al., 2008).

\section{PROCEDIMENTOS METODOLÓGICOS}

0 presente trabalho caracteriza-se como uma pesquisa qualitativa que, segundo Silva, Gobbi e Simão (2004) é utilizada para compreender o significado que situações particulares representam para os indivíduos daquele contexto. Além disso, trata-se de uma pesquisa de cunho descritivo e exploratório, por abordar e descrever as atitudes de jovens no que diz respeito à abordagem do tabagismo como publicidade em clipes do gênero pop.

A pesquisa qualitativa é um estudo fundamentalmente interpretativo. 0 que o autor da pesquisa realiza é apenas a interpretação de dados e cenários conseguidos e observados durante o desenvolvimento da investigação, tirando conclusões sobre seu significado. (Creswell, 2007). Serapioni (2000) afirma que o método deve ser utilizado quando o objeto de estudo ainda não é muito conhecido, justamente devido a sua capacidade de ousar por novos aspectos e buscar ir ao fundo no contexto. Isso justifica o caráter exploratório da pesquisa.

A coleta de dados desta pesquisa ocorreu por meio da técnica "entrevista" que segundo Bauer e Gaskell (2015), é uma partilha de realidades e uma metodologia de coleta de dados amplamente utilizada nas ciências sociais e, conforme explicam Marconi e Lakatos (2007), é um procedimento utilizado nas pesquisas sociais a fim de ajudar a diagnosticar e resolver problemas sociais, tal qual o problema mundial do tabagismo. Quando aplicada ao método qualitativo, Bauer e Gaskell (2015) afirmam que a entrevista fornece dados para o desenvolvimento e a compreensão detalhada das relações entre a situação específica e seus atores sociais, sendo esses dados a sua condição sine qua non.

Para Bauer e Gaskell (2015), a entrevista visa explorar as diferentes opiniões sobre um determinado tema. Assim, a escolha desta técnica é justificável na medida em que o objetivo é exatamente obter os pontos de vista a respeito do tabagismo aplicado aos clipes pop. Trata-se de uma entrevista estruturada que, 
segundo Bauer e Gaskell, (2015), é uma forma de guiar a entrevista. 0 autor explica que conduzir a entrevista com perguntas funciona como um convite para os mesmos refletirem com calma e responderem longamente sobre o que lhes foi exposto.

Com relação à segmentação do grupo entrevistado, levou-se em consideração a idade e a educação do grupo. Propõe-se avaliar as atitudes de jovens que, diferente dos citados em estudos deste gênero, possuem acesso à educação. Dito isto, é justificável também a escolha do Centro Acadêmico do Agreste como lócus da pesquisa, por os seus integrantes pertencerem a cursos de graduação. Em contrapartida, não foram empregados critérios de gênero, raça ou nível de renda, procurando serem os mais diversos possíveis, a fim de não haver quaisquer vieses nas respostas.

Foram realizadas 10 entrevistas entre os dias 12 de maio de 2016 a 25 de maio de 2016, onde foi estabelecido com os participantes uma relação de rapport, ou seja, onde foi criado um ambiente agradável antes das perguntas, estabelecendo uma conversa prévia e amigável com os entrevistados, numa sala vazia, tranquila e livre de calor, barulhos ou qualquer outro personagem que atrapalhasse a conversa, a fim de que os mesmos se sentissem à vontade e confiantes para responder de forma longa e expansiva sobre alguns aspectos de suas vidas, abordando-os com sinceridade e o menos superficial possível (Bauer e Gaskell, 2015).

Os entrevistados não fumantes foram escolhidos aleatoriamente, de acordo com a disponibilidade de tempo dos mesmos. Já os fumantes foram escolhidos por meio de sugestões dos alunos do CAA que indicavam conhecidos seus que eram fumantes. Ambos os grupos foram abordados nos corredores da Universidade e questionados sobre a possibilidade de participar de uma pesquisa para um trabalho de conclusão de curso. Procurou-se não informar aos entrevistados o tema da pesquisa a fim de suas respostas não serem influenciadas. Ao concordarem em participar, os respondentes foram conduzidos para uma sala vazia com as condições citadas no parágrafo acima.

Uma vez estabelecida a condição de bemestar, os clipes foram apresentados seguindo uma ordem padrão, qual seja: (1) We Found Love - Rihanna; (2) Locked Out Of Heaven -
Bruno Mars. Imediatamente após a exibição dos vídeos, foram feitas as perguntas (14 para os não fumantes e 16 para os fumantes) num roteiro previamente articulado. Ao término das respostas, as entrevistas gravadas eram pausadas e o entrevistado liberado.

Foram-lhes apresentados dois clipes escolhidos entre os $10 \mathrm{com}$ mais visualizações retirados dos 63 vídeos analisados por Silva (2015). A partir disso, foram escolhidos os dois utilizados aqui, por possuir relevância e destaque entre os demais estudados pela autora. Uma vez que tais vídeos abordam o cigarro como um ato de liberdade, felicidade, sex appeal e, por vezes, conteúdo machista. Além disso, foram escolhidos, estrategicamente, um artista do sexo masculino e outro do sexo feminino, a fim de retratar os dois aspectos da mesma abordagem.

Os videoclipes escolhidos estão entre os 10 mais visualizados no YouTube, entre os clipes que figuram entre os 10 primeiros da Hot100 da Billboard entre 2005 e 2015 nos quais há a inserção de cigarro ou promoção do hábito de fumar. Os vídeos escolhidos para elucidar as entrevistas são: We Found Love, da cantora Rihanna e Locked Out From Heaven, do cantor Bruno Mars. A escolha dos dois considerou a diversidade de gênero dos artistas, a diversidade de contexto em que o cigarro é inserido e a diversidade de público que acompanha ou não os artistas. Antes de apresenta-los aos entrevistados, foi feita uma prévia análise e descrição dos mesmos, as quais serão apresentadas nos apêndices deste trabalho.

Entre os dez entrevistados, cinco fumantes e cinco não fumantes, foram escolhidos aleatoriamente cinco homens e cinco mulheres, com idade entre 19 e 30 anos dos cursos de Administração, Economia, Química, Matemática e Pedagogia da Universidade Federal de Pernambuco (UFPE), Centro Acadêmico do Agreste (CAA). As entrevistas estruturadas foram registradas via gravação de voz. As mesmas tiveram duração entre 16 e 34 minutos cada uma e aconteceram sob a disponibilidade de tempo dos entrevistados.

Dentre os cinco fumantes, três eram homens de 30,25 e 21 anos e duas eram mulheres de 27 e 19 anos. Entre os não fumantes, três foram mulheres de 23, 22 e 21 anos e dois foram homens, ambos de 22 anos. Os mesmos serão 
descritos aqui em dois grupos: fumantes grupo 1; e não fumantes - grupo 2. Abaixo, no quadro 1, serão apresentados os dados de cada entrevista

$\begin{array}{cccccc}\text { Entrevista } & \text { Gênero } & \text { Classificação } & \text { Idade } & \text { Curso } & \begin{array}{c}\text { Duração } \\ (\text { min:seg })\end{array} \\ \text { E1 } & \text { Masculino } & \text { Fumante } & 25 & \text { Economia } & 16: 22 \\ \text { E2 } & \text { Masculino } & \text { Fumante } & 30 & \text { Economia } & 24: 21 \\ \text { E3 } & \text { Feminino } & \text { Fumante } & 27 & \text { Pedagogia } & 21: 05 \\ \text { E4 } & \text { Feminino } & \text { Fumante } & 19 & \text { Pedagogia } & 12: 24 \\ \text { E5 } & \text { Masculino } & \text { Fumante } & 21 & \text { Matemática } & 19: 03 \\ \text { E6 } & \text { Masculino } & \text { Não fumante } & 22 & \text { Economia } & 19: 50 \\ \text { E7 } & \text { Feminino } & \text { Não fumante } & 22 & \text { Administração } & 23: 20 \\ \text { E8 } & \text { Masculino } & \text { Não fumante } & 22 & \text { Economia } & 33: 31 \\ \text { E9 } & \text { Feminino } & \text { Não fumante } & 21 & \text { Administração } & 18: 50 \\ \text { E10 } & \text { Feminino } & \text { Não fumante } & 23 & \text { Química } & 23: 16\end{array}$

Fonte: Dados da pesquisa.

Figura 1. Descrição das entrevistas.

A análise de dados desta pesquisa foi realizada a partir da estratégia análise de conteúdo, que leva em consideração a interpretação subjetiva do indivíduo dentro de sua própria realidade (Silva, Gobbi \& Simão, 2004). Para os autores, a técnica consiste em decompor discursos a fim de categorizar fenômenos a partir de uma reconstrução de significados. Assim, é possível formular uma nova interpretação do grupo estudado. (Silva, Gobbi \& Simão, 2004; Mozzato \& Grzybovski, 2011).

Ainda sob a ótica de Silva, Gobbi e Simão (2004), a análise de conteúdo é uma ferramenta de construção do significado dos discursos exteriorizados pelos indivíduos, a respeito da realidade vivida por eles. Para os autores, a técnica não requer etapas rígidas, mas uma reconstrução das percepções dos entrevistados, levando em consideração todas as nuances do discurso, como pausas, repetições e o próprio conceito.

Para facilitar no padrão e interpretação das respostas, os videoclipes foram apresentados aos entrevistados seguindo uma sequência fixa, sendo o primeiro vídeo We found love da cantora Rihanna e o segundo Locked out of heaven, do cantor Bruno Mars. E a fim de preservar as identidades dos respondentes, eles serão descritos neste trabalho por meio da letra "E". Sob esses aspectos, as respostas dos entrevistados foram analisadas e agrupadas em duas tabelas que retratam a essência de suas respostas, sendo $\mathrm{E}$ a linhado entrevistado e $\mathrm{Q}$ a pergunta correspondente de cada coluna.

\section{ANÁLISES E DISCUSSÕES \\ Do envolvimento com os clipes}

Todos os que responderam sentir algum tipo de envolvimento pelos clipes/música atribuíram isso ao fato deles serem animados e lembrarem festa e diversão. Tal questionamento foi importante para entender que, assim como afirma Mooij (2011), as atitudes e os comportamentos de consumo são um resultado de componentes afetivos e cognitivos de sensações, sentimentos e emoções. Neste caso, observou-se que a maioria daqueles que responderam sentir ou atribuir alguma forma de prazer aos videoclipes são fumantes ou são contra algum tipo de proibição e restrição do cigarro. Ou seja, quem alegou sensações positivas a respeito dos clipes, possui pelo menos algum tipo de atitude favorável ao consumo e/ou exibição do conteúdo de tabaco. Assim, pode-se dizer que Mooij (2011) tem razão ao dizer que as atitudes têm a ver com sentimentos.

\section{Dos elementos utilizados}

Quando questionados se houve alguma característica marcante nos clipes, o ponto mais comentado foi a felicidade efêmera apresentada nos mesmos. A busca e a retratação da felicidade baseada no desequilíbrio, na falta de afeto e nas brigas. Também foram citados os 
usos exacerbados do cigarro, das drogas e do sexo. Todos os entrevistados identificaram o uso do cigarro nos videoclipes. Destes, alguns deles descreveram o uso como comum e normal. Dois dos respondentes - um fumante e um não fumante - atribuíram características positivas à apresentação do tabaco nos clipes.

A presença de inúmeros apelos audiovisuais, destacados pelos entrevistados, a respeito da aparição do cigarro nos videoclipes, como o sexo, festa, diversão, êxtase, etc. também corrobora com Solomon (2002) e o seu Paradoxo do Envolvimento, onde estímulos como contexto, ambiente retratado e promessa de alegria fazem com que os expectadores façam associação a coisas boas e integrem o sentimento ao produto. Tal fato não se mostrou verdade na pesquisa, visto que, apesar dos sentimentos positivos que os clipes lhes causaram, apenas dois dos entrevistados associaram o sentimento à figura do cigarro.

Um grupo de entrevistados citou explicitamente a nudez e a sensualidade em pelo menos um dos videoclipes e atribuiu isso a algo bom. Esta informação nos leva a lembrar das afirmações de Mooij (2011), Lindstrom (2009) e Shimp (2009) que cominam o sexo retratado na publicidade como um atributo que tende a chamar atenção e vender o produto, sendo capaz de melhorar a associação favorável com o mesmo, bem como estender o "prazo de vida útil" da publicidade na mente dos expectadores.

Além disso, é curioso verificar que a visão de Mooij (2011) a respeito da percepção desse conteúdo é distorcida na pesquisa, uma vez que três dos que citaram a sensualidade e a nudez eram homens, e não mulheres, como o autor afirmou possuírem maior facilidade em identificar cenas com esse tipo de conteúdo.

\section{Da relação com o endossante}

Todos os entrevistados acreditam que pelo menos um dos videoclipes apresentados influencia de alguma maneira o consumo de cigarros. Com relação à influência de artistas sobre adolescentes, todos os entrevistados concordam que ícones pop possuem papel de destaque na hora de influenciar jovens adolescentes a pensar ou agir de determinado modo, seja pela falta de maturidade ou por enxergarem em seus ídolos a imagem a ser seguida.

Esta informação anda em conformidade com o conceito de endosso, destacado neste trabalho, por Shimp (2009), no qual o endossante é utilizado como uma via de transmissão de confiabilidade, atração física, respeito e conexão com o público, que por sua vez atribui tais características a tudo o que o artista faz uso (Conceição et al., 2014). Neste caso, o cigarro. É o modelo TEARS.

Pode-se perceber que a maioria daqueles que responderam conhecer os artistas dos clipes, se mostraram favoráveis à exibição do produto nos videoclipes ou consideraram o uso como algo normal. Entre os não fumantes as respostas variaram. Com exceção de E10, mesmo os que disseram gostar dos artistas dos clipes, foram a favor de haver algum tipo de controle sobre a exibição deles por não considerarem conteúdos adequados para todos os públicos. Ou seja, a relação estabelecida dentre os fumantes entre aprovar a exposição do cigarro em videoclipes e a identificação com o artista não se repete com não fumantes.

Ainda assim, no grupo dos não fumantes, aqueles que responderam conhecer os cantores mostraram não considerar o ato de fumar, ou mesmo a sua exposição, algo totalmente ruim. Mesmo assim, ponderaram a sua limitação e controle ao público infantil e adolescente.

E1 afirma que:

\begin{abstract}
"Incentivam porque ele vai se sentir parte do grupo. Principalmente se no grupo tiver alguém fumante. Como se fosse uma coisa, não proibida, mas que o estímulo mesmo se dá por uma proibição virtual ou real, mas a pessoa vai 'ow, velho. Fulano é descolado, aí fuma, tal'”.
\end{abstract}

Isso já havia sido observado nesta pesquisa, a partir da abordagem da atitude expressiva de valor, que enxerga a atitude como uma busca por identidade social. Ou seja, a visão e o uso do cigarro estão não só ligados à percepção que o indivíduo tem do produto, mas também do que é atrelado a ele, seja aceitação social, busca por status, imagem a ser seguida, rebeldia, etc. É também o que Solomon (2002) explica: a atitude é um conjunto de no mínimo três elementos da vida física e/ou emocional. 
Apesar de comprovada por diversos estudiosos, como Araújo (2010) e Conceição et al. (2014), citados nesta pesquisa, o endosso de artistas para propaganda do cigarro nos videoclipes não foi identificada nem reconhecida como real aos olhos de todos os entrevistados. Três deles disseram que isso não seria possível e não acreditam na existência de algo assim. Tal fato pode representar uma ingenuidade dos respondentes mais vulneráveis às ações de publicidade da mídia. Assim como eles, milhares de outros jovens no mundo inteiro são influenciados pelo endosso de artistas todos os dias, sem perceber.

Além disso, dos fumantes, dois deles disseram que ver outra pessoa fumar influencia a querer fumar também. E1 disse que já estava com vontade de fumar, mas aumentou depois dos clipes. E2 afirmou que não estava com vontade de fumar, pois havia fumado pouco antes da entrevista, mas que ver outra pessoa fumando o induz a querer fumar mais. Ele disse que:

"Não porque eu tinha acabado de fumar. Mas só que aí às vezes o fumante é um cara esquisito. Não tá com vontade de fumar, mas vê um cara fumando aí lembra que fuma e vai lá... [...] Aí eu acho que não tive vontade de fumar porque eu já tinha fumado, mas induz".

E3 e E5 disseram já estar com vontade de fumar antes e que isso não tinha relação com os clipes. Eles disseram, respectivamente:

"Hoje eu ESTOU com vontade de fumar. Mas não, não é porque eu vejo alguém fumando assim, eu não tenho esse tipo de estímulo assim. É mais interno, é mais você mesmo, independente dos estímulos, é isso. Acho que é isso".

"Bom, na verdade, quando eu saí da sala eu estava com vontade de fumar, mas quando 'tava' aqui não".

E E4 disse não estar com vontade de fumar. Ou seja, verifica-se que, inicialmente, os clipes em si não induzem o desejo de fumar, mas o fato de um fumante ver outra pessoa, independente de ser um artista ou não, libera o desejo consciente, ou não, do fumo.

\section{Da proibição e controle}

Cinco dos entrevistados, três deles não fumantes, concordaram que clipes com conteúdo de tabaco como os apresentados, deveriam ser proibidos de veiculação para menores de 18 anos. Destes, apenas dois eram fumantes que, curiosamente, foram os dois mais velhos da pesquisa. Um deles (E1) afirmou que o cigarro é a porta de entrada para outras drogas. Ele disse que:

\begin{abstract}
"Deveria, né. Com certeza. Porque, eu pelo menos tenho uma ótica de que às vezes é a entrada pra outras drogas, com certeza são as drogas ilícitas, né. De uma certa maneira é proibida para menores, mas através de outros meios eles conseguem. Então, com certeza. Era pra ser".
\end{abstract}

Dois participantes, um fumante e outro não fumante, se posicionaram a favor da proibição, mas alegaram que o cigarro não é a única coisa que deveria ser proibida. Os demais se mantiveram contra a proibição por achar que o consumo independe de incentivos como esses, além do ato de proibir interferir na liberdade do indivíduo.Mesmo assim, seis dos entrevistados, quatro não fumantes e dois fumantes, mais uma vez os dois mais velhos, afirmaram que são contra a veiculação de vídeos com conteúdo de tabaco, por não serem adequados para o público. E9, o único não fumante que foi contra a ideia, afirma que o fato é apenas o exercer da liberdade de expressão e limitar isso é restringir os artistas no que eles consideram bom. Ele afirma que:

“É complicado. Porque deveria ser avaliado caso a caso. Porque tem aquele ditado do que é proibido é mais gostoso, dá mais vontade de se ter? Eu acho que parte tudo da questão da educação. De você ter uma cadeia de princípios bem levada, de ter pais responsáveis que lhe mostrem 'você está vendo isso? Tá. Isso é o que acontece, mas isso não é certo. Não faça isso, isso não vai lhe trazer benefícios'. Acho que vai muito disso. Acho que proibir não é o caminho não. Nunca foi e nunca vai ser. No caso é minha opinião. Educação. Base familiar. Pelo menos na minha cabeça isso é fundamental. Independente de proibir ou não. Porque assim, é aquela questão da liberdade de expressão. Se você quer fazer aquilo, a gente vive num mundo livre. Se você quer fazer 
aquilo, agir daquela forma, se você acha legal se expressar assim, se acha que as pessoas vão entender daquela forma. Eu acho adequado sim. Não vejo nenhum problema, restrição... De minha parte justamente se você quer se expressar assim, se você acha que aquilo que você está mostrando é certo, é o que você está sentindo? Por mim, tudo bem".

Os demais contra a proibição são fumantes que alegam que o tabaco é algo normal e menos prejudicial que outros tipos de drogas, lícitas ou não.

Apesar de comprovado cientificamente que a proibição da exibição do cigarro seja eficaz na redução do consumo e que a proibição parcial não influencia nos resultados da questão (Mirra et al., 2013), apenas seis dos entrevistados se mostraram favoráveis à criação de restrições da apresentação do cigarro em videoclipes. E, destes, nenhum se mostrou favorável à proibição total da criação desse tipo de conteúdo.

Sete pessoas classificaram os clipes como uma forma de publicidade. E3 afirmou que não é publicidade, mas vende porque vai à mídia; e E5 alegou ser apenas a expressão do artista. A opinião de E3 corrobora, de certa maneira, com Santos e Grossi (2006) quando os mesmos afirmam que a mídia transmite verdades que são incorporadas em nosso senso comum.A respeito disso, E8 afirma o seguinte:

"Eu acredito que eles não bolam um clipe, bolam um comercial. Porque se eles levarem em consideração que ambos são comerciais, só tem uma musica de fundo e o cantor que está na frente canta a música, então não muda em nada o conceito de comercial. Só muda que não aparece uma logomarca no começo, um slogan durante e a logomarca novamente no final. Mas propriamente dito, é uma apologia. Então eu acho que sim. [...] A nossa mente não capta, mas nosso subconsciente nos envolve por trás e nos coloca nessa situação [de] 'vai', entendeu? [...] Então eu acho que subliminarmente existe o interesse por trás, mesmo que o autor não saiba, mesmo que o produtor não saiba, mas existe ali subliminarmente uma estratégia de marketing. [...] Embora a gente não veja na televisão clipes como esses, mas a gente vê reportagens, matérias, a gente sempre tem o pessoal bebendo, sendo entrevistado na mesa de bar ou então numa festa, numa have, o Rock in Rio, por exemplo, se assemelha muito. Então aí você percebe".

A idade que os cinco fumantes iniciaram o hábito do fumo varia, mas todos tiveram sua primeira experiência com o cigarro na adolescência. E1 foi o mais precoce com 11 ou 12 anos. 0 mesmo afirmou ter experimentado o primeiro cigarro como forma de rebeldia. Ir contra os padrões pré-estabelecidos para ele, o que comprova a discussão estabelecida nesta pesquisa sobre a relação da busca da identidade do jovem e a rebeldia. Dos entrevistados fumantes, apenas E2 disse se considerar viciado.

Todas estas respostas corroboram com as ideias de Katz (1960) e Solomon (2002), quando afirmaram que cada indivíduo possui uma diferente atitude sobre determinado tema. Neste caso, verificou-se que, assim como na teoria, os jovens, fumantes e não fumantes, possuem diferentes atitudes com relação ao cigarro por a referência do mesmo gerar prazer ou dor. De todo modo, estabelecem-se diferentes atitudes de consumo a respeito do cigarro entre esses jovens.

\section{Fumantes versus não fumantes}

No geral, pode-se concluir que os fumantes possuem maior facilidade em demonstrar atitudes positivas em relação ao tabaco dos videoclipes. Em contrapartida, os não fumantes, na maioria das vezes, se mostraram cuidadosos em suas respostas a respeito do conteúdo dos clipes, atribuindo aos mesmos a ideia de escuridão e fuga de algo, um refúgio.

Nota-se que antes de questionados a respeito da existência do tabaco nos videoclipes, apenas um fumante citou o uso do cigarro como algo marcante no clipe. Por outro lado, a atitude dos não fumantes não se mostrou ser muito divergente disso, visto que apenas dois deles atribuíram ao cigarro a característica marcante dos clipes antes de questionados a respeito disso. Os demais se mantiveram indiferentes à existência do cigarro até o tema ganhar foco nas perguntas da entrevista. Tal fato é curioso uma vez que demonstra que a presença do cigarro é pouco comentada a menos que seja posta em atenção. Não se trata de algo extraordinário e não ganha espaço na mente das pessoas por ser algo comum. 
Para a maioria dos fumantes, o endosso de artistas é algo que funciona. A visão que a maioria deles possui é de que os artistas influenciam, mesmo que os mesmos não se considerem influenciados por eles. A atitude dos jovens fumantes é de atribuir a influencia do endossante àqueles que são fãs dos artistas e a jovens adolescentes. Mesmo assim, tanto no grupo dos fumantes como no grupo dos não fumantes, é possível verificar que a atitude dos jovens que conhecem o artista e seu trabalho tende a ser mais favorável ao cigarro do que dos jovens que disseram não conhecer ou não gostar dos mesmos. Ou seja, quando o endosso foi apresentado a pessoas que apreciam os cantores, as respostas tenderam a atribuir a responsabilidade da influencia a outros elementos, como a família e os amigos. 0 fato é ainda mais visível entre os fumantes.

Em relação à atitude de encarar os clipes como um tipo de publicidade, todos os não fumantes foram a favor. Já entre os fumantes, é curioso observar que a maioria não considera publicidade e os que consideram acreditam que isso é algo ruim por mostrar o lado mau do fumo. E1 afirma que:

"Poder pode, né. Mas não deveria. Qual o sentido de utilizar isso como publicidade e propaganda se as externalidades são negativas? Não tem nenhuma positiva [...]".
Com isso, os não fumantes mostram que é perfeitamente normal videoclipes influenciarem o consumo, enquanto os fumantes mostram ser contra a ideia de que algo pode ser mostrado como prejudicial ao fumo e atribuem o ato de fumar a algo mais interno do que decorrentes de fatores exteriores, como artistas fazendo uso do tabaco em clipes.Por fim, a maioria dos jovens não fumantes acredita que o controle e a regulação da exibição de tabaco em videoclipes devem existir. Em compensação, a atitude dos jovens fumantes é se posicionar mais contra do que a favor da regulação.

Além de todos os pontos abordados nesta pesquisa, é interessante destacar a importância de estudar se existe alguma relação entre o grau de educação recebida pelos jovens e as suas atitudes com relação ao cigarro. Essa questão leva a discussão se as respostas dos entrevistados desta pesquisa podem ter sido influenciadas, de alguma maneira, pelo fato de serem estudantes de uma graduação; e se fossem jovens de periferia as respostas seriam diferentes.

A seguir, será apresentado um quadro que apresenta as principais divergências entre fumantes e não fumantes, obtidas a partir das análises desta pesquisa.

\begin{tabular}{|c|c|c|c|c|c|c|}
\hline & $\begin{array}{l}\text { Atitude em } \\
\text { relação ao tabaco } \\
\text { em clipes }\end{array}$ & $\begin{array}{l}\text { Cigarro como } \\
\text { algo } \\
\text { marcante }\end{array}$ & Endosso & $\begin{array}{l}\text { Clipe como } \\
\text { publicidade }\end{array}$ & $\begin{array}{l}\text { O hábito é } \\
\text { causado por }\end{array}$ & Controle \\
\hline Fumantes & Positiva/normal & Não notou & Funciona & Discordam & $\begin{array}{l}\text { Questões } \\
\text { internas }\end{array}$ & Discordam \\
\hline $\begin{array}{l}\text { Não } \\
\text { fumantes }\end{array}$ & Cuidadosa & Não notou & Funciona & Concordam & $\begin{array}{l}\text { Influências } \\
\text { externas }\end{array}$ & Concordam \\
\hline
\end{tabular}

Fonte: Elaborados pelos autores.

Figura 2. Relação entre fumantes e não fumantes

\section{CONSIDERAÇÕES FINAIS}

Esta pesquisa teve como objetivo geral analisar as atitudes apresentadas por jovens frente à inserção de cigarros em videoclipes. A partir daí, observou-se que os jovens fumantes são mais liberais e quase não enxergam problemas na veiculação de tal conteúdo. Os fumantes também não acreditam que os clipes possam influenciar e creem que a proibição deve se restringir apenas a crianças. 0 grupo se envolveu mais facilmente com os videoclipes e atribuiu características e sentimentos bons aos vídeos. Não houve nenhuma diferença, nos fumantes, se a apresentação do cigarro foi feita de maneira positiva ou negativa. 0 estímulo se deu essencialmente por ver outra pessoa fumar.

Em contrapartida, os jovens não fumantes se mostraram mais restritivos em relação à apresentação do cigarro nos clipes. Ademais, os 
lados negativos dos clipes foram enxergados e destacados com mais facilidade.Jovens não fumantes enxergaram mais problemas na exposição de vídeos com conteúdo tabagístico por atribuírem a eles forte grau de influência em jovens adolescentes. Nenhum deles acredita ter sido influenciado, ou que poderia ser, em outras circunstâncias, pelos videoclipes. 0 grupo acredita que o cigarro é um estilo de vida e existem problemas piores que ele. Contudo, todos os membros do grupo revelaram achar os videoclipes uma forma de publicidade.

Aqueles que disseram conhecer e/ou gostar dos artistas se mostraram mais favoráveis ao cigarro exposto nos clipes, independente se fumante, ou não. Ou seja, o endosso do cigarro realizado com artistas influencia a maneira como eles enxergam o fumo. É possível concluir que a possível nova publicidade de cigarros em videoclipes musicais acarreta novos sentimentos e atitudes nos jovens. Ambos os grupos acreditam que o endosso de artistas pode influenciar, mas os fumantes restringem isso a quem é fã, enquanto os não fumantes dizem influenciar a todos, menos a eles. Pode-se perceber que fumantes são facilmente influenciados pela apresentação do cigarro, independente do artista endossante, enquanto jovens não fumantes são influenciados pelo artista e sua afinidade com ele/ela.

Quanto à proibição e/ou restrição, ambos os grupos se mostraram favoráveis à aplicação de tal, de maior ou menor maneira. Os não fumantes bem mais que os fumantes. 0 merchan music voltado ao tabaco se mostrou viável, mas de formas diferentespara fumantes e não fumantes. Chega-se a conclusão de que ele não determina se um indivíduo vai fumar ou não, mas é um estímulo para o uso em jovens fumantes e uma referência para jovens não fumantes. Se não controlado e restringido agora, pode vir a representar um retrocesso na luta contra o marketing positivo do tabaco.

\section{REFERÊNCIAS}

ACT. Aliança de Controle do Tabagismo. (2007). Brasil gasta $\mathrm{R} \$ 21 \mathrm{bi}$ com tratamento de doenças relacionadas ao tabaco. Recuperado de: <http://actbr.org.br/>.

ACT. Aliança de Controle do Tabagismo. (2011). Porque a indústria do tabaco deve ressarcir os gastos do SUS no tratamento de doenças tabaco-relacionadas.. Recuperado de: $<$ http://actbr.org.br/>.

Araújo, A. J. (2010). Tabagismo na adolescência: Por que os jovens ainda fumam? Jornal Brasileiro de Pneumologia, 36(6).

Bauer, M. W., Gaskell, G. (2015). Pesquisa qualitativa com texto, imagem e som: Um manual prático. 13a ed. Petrópolis, RJ: Vozes.

Borges, M. T. T; Barbosa, R. H. S (2009, junho/julho). As marcas de gênero no fumar feminino: uma aproximação sociológica do tabagismo em mulheres. Ciência \& Saúde Coletiva, 2(14). 1129-1139.

Brasil. Lei n. 12.546, de 14 de dezembro de 2011 (2011, 14 de dezembro). Recuperado de: <http://www.planalto.gov.br/ccivil_03/_ato2 011-2014/2011/lei/l12546.htm>.

Brasil. Lei n. 9.294, de 15 de julho de 1996 (1996, 15 de julho). Recuperado de: <http://www.planalto.gov.br/ccivil_03/leis/L 9294.htm>.

Cardoso, P. R \& Gomes, N. \& Freitas, E. S. L. (2010, março). O papel da música nos anúncios publicitários de televisão: uso estratégico e impacto no consumidor. Comunicação, mídia e consumo, 18(7), 11-35.

Coelho, P. F. C., (2015, julho/setembro). A pesquisa tranformativa do consumidor: Reflexões e diretrizes para pesquisadores brasileiros. $E \& G$ Economia e Gestão, 40(15), 4-27.

Conceição, A. et al (2014). Merchan Music- A arte de vender através da música: Uma análise do videoclipe Live it $\mathrm{Up}$ da cantora Jennifer Lopez. In: INTERCOM - Sociedade Brasileira de Estudos Interdisciplinares da Comunicação. 16., João Pessoa, PB.

Creswell, J. W (2007). Projeto de pesquisa: Método qualitativo, quantitativo e misto. (2 ${ }^{\mathrm{a}}$ ed.). Porto Alegre: Artmed.

Filho, G. G. \& Caprino, M. P (2006). A propaganda de cigarro: Eterno conflito entre público e privado. In: UNESCOM - Congresso Multidisciplinar de Comunicação para o Desenvolvimento Regional. 2006, São Bernardo do Campo - SP. Brasil.

Katz, D (1960). The functional approach to the study of attitudes. Public Opinion Quarterly, 24(2), 163-204.

Lindstrom, M. (2009). A lógica do consumo: Verdades e mentiras sobre por que compramos. Rio de Janeiro: Nova Fronteira.

Lipovetsky, G. (2000, junho/dezembro) Sedução, publicidade e pós-modernidade. Revista FAMECOS, 12, 7-13.

Lovison, A. M. \& Petroll, M. de La M. (2011, junho). Ética na publicidade e propaganda: A visão do executivo de agências de comunicação do Rio 
Grande do Sul. Cadernos EBAPE.BR, 9(2), 333359.

Marconi, M. De A. \& Lakatos (2007). Técnicas de pesquisa. São Paulo: Atlas.

Mick, D. G. (2006) Meaning and mattering thougt trasformative consumer research. Advanced in Consumer Research, 33.

Mirra, A. P. et al. (2013, março). Evidências científicas sobre o tabagismo para subsídio ao poder judiciário. Associação Médica BrasileiraProjeto Diretrizes.

Mooij, M. K. (2011). Consumer behavior end culture: Consequences for global marketing and advertising. $2^{\mathrm{a}}$ ed. Londres: SAGE Publications.

Moutinho, A. V. (2008). Publicidade, tabaco e estratégias. Actas III Jornada de Publicidade e Comunicação. Portugal: Universidade Fernando Pessoa. p. 1-7.

Muniz, E. (2004). Publicidade e propaganda: Origens histórias. Caderno Universitário, 148.

Randall, V. R. (1999). History of tobacco. Recuperado de:

<http://academic.udayton.edu/health/syllabi /tobacco/history.htm>.

Reinaldo, M. A. S. et al. (2010). Uso de tabaco entre adolescentes: Revisão de literatura. SMAD, Revista Eletrônica Saúde Mental Álcool $e$ Drogas, 6(2), 351-364.

Reis, A. (2012, novembro). A História do Cigarro: A evolução de um produto polêmico. Recife. Recuperado de: <http://professorarturreis.blogspot.com.br/2 012/11/a-historia-do-cigarro-evolucao-deum.html>.

Romero, N. L. \& Centellas, F. C. (2008). New stages, new narrative forms: The web 2.0 and audiovisual language. Recuperado de: <http://www.upf.edu/hipertextnet/en/nume ro-6/lenguaje-audiovisual.html>.

Romero, L. C. \& Silva, V. L. da C. (2011). 23 anos de controle do tabaco no Brasil: A atualidade do programa nacional de combate ao fumo de 1988. Revista Brasileira de Cancerologia, 57(3), 305-314.

Santos, A. M. \& Grossi, P. K. (2007, julho/dezembro). Infância comprada: hábitos de consumo na sociedade contemporânea. Textos \& Contextos, 2(6), 443-454.
Sasaki, S. (2010). Smoking fetish: Representações femininas nas propagandas de cigarro (19401960). Diásporas, diversidade, deslocamentos. Recuperado de: <http://www.fazendogenero.ufsc.br/9/resou rces/anais/1277920551_ARQUIVO_SmokingF etish_SilviaSasaki_Texto_Competo_FG9.pdf>

Serapioni, M. (2000). Métodos qualitativos e quantitativos na pesquisa social em saúde: Algumas estratégias para a integração. Ciência \& Saúde Coletiva, 1(05).

Silva, J. M. da. (2015). O discurso na fumaça: As estratégias publicitárias utilizadas em videoclipes de música pop para incentivar o consumo de cigarros. Um estudo na perspectiva transformativa do consumidor. (Monografia Graduação em Administração) - Universidade Federal de Pernambuco, Caruaru, PE.

Shimp, T. A. (2009). Comunicação integrada de marketing: Propaganda e promoção. 7ạ ed. Porto Alegre: Bookman.

Soares, T. (2012). Videoclipe: O elogio da desarmonia. Ed. Marca de Fantasia. Série Periscópio 22. João Pessoa-PB.

Soares, T. (2008). 0 videoclipe como performance da canção: Apontamentos para uma análise midiática. In: INTERCOM - Sociedade Brasileira de Estudos Interdisciplinares da Comunicação, 10., São Luis, MA. Anais. São Luis.

Solomon, M. R. (2002). O comportamento do consumidor: comprando, possuindo e sendo. $5^{\mathrm{a}}$ ed., Porto Alegre: Bookman.

Think With Google. (2015). Intimidade dos brasileiros com o YouTube. Recuperado de: <https://www.thinkwithgoogle.com/intl/ptbr/articles/intimidade-dos-brasileiros-comyoutube.html >.

Vergara, R. \& Aquino, M. (2003, junho) Ascensão e queda do Tabaco. Superinteressante, 189a ed.

Zanetti, D. \& Belo, R. (2012, setembro/dezembro). Da TV para a Web 2.0: Os novos usos do videoclipe. Contemporânea - Revista Comunicação e Cultura, Bahia, 03(10). p. 777793.

\section{The Voices of the Addiction: The Attitudes of Young Smokers and Non-smokers Regarding to Endorsing the Consumption of Cigarettes in Videoclipes}

Abstract: This research aims to analyze the attitudes displayed by young people across the insertion of cigarettes in video clips. This is a descriptive and exploratory research, looking for your answers from the direct and interactive relationship with the researched from individual interviews in order to understand 
A Voz do Vício: As atitudes de jovens fumantes e não-fumantes quanto ao endosso do consumo de cigarros em videoclipes

the phenomenon from the perspective of the respondent. For that were presented two clips among the most viewed Billboard and data analysis was made from the technical content analysis. At the end of the survey, you will notice that (1) young smokers are more liberal than non-smokers regarding the display of cigarettes in video clips; (2) marketing is successful while seeing other people smoking affects smokers continue the habit; (3) Friends, family and status influences as much as seeing someone else and smoking; (4) the use of endorsers in this type of merchandising is successful in the eyes of anyone who admires artists.

Keywords: Merchan music, Consumer attitude, Cigarette, YouTube, Endorsers. 